\title{
A Short Summary of Present Knowledge and Some Experimental Observations on the Ductility of Sub-microcrystalline Aluminium Alloys
}

\author{
Maurizio Ferrante
}

\author{
Department of Materials Engineering, Federal University of São Carlos, São Carlos - Brazil
}

Keywords: ductility, aluminium alloys, ECAP, work-hardening, tensile strength

\begin{abstract}
It is well known that the low ductility of nanostructured materials seriously impairs their commercial development. In its turn that mechanical property is associated to the work-hardening behaviour and the vast literature on this relationship is a measure of its importance. This paper presents a short review of the basic models of work-hardening, dealing initially with conventional "coarse" grain metals and alloys, then moving to the behaviour of sub-microcrystalline materials within the bounds of Al alloys and Equal Channel Angular Pressing. Finally, the interrelations of tensile properties, work-hardening behaviour and microstructure are illustrated by data obtained on a precipitation and a non-precipitation hardening $\mathrm{Al}$ alloys, namely $\mathrm{Al}-4 \% \mathrm{Cu}$ and $\mathrm{AA} 3004$. Results show that low temperature aging results in higher strength and high work hardening rate, besides high ductility. The effects of precipitation and of annealing heat treatments are discussed.
\end{abstract}

\section{Introduction}

Among the mechanical properties of structural materials, ductility is particularly important since it relates to fracture toughness and formability. It can be assessed by the tensile test, simply by recording the specimen elongation, or better, its section reduction.

The attraction that nanostructured materials exert on the scientific community was originally motivated by noticing a dramatic strength enhancement and realizing that grain size reduction was the basis of the phenomenon. Further research was driven by the need to better understand and control this cause-effect relationship, rationalize the mechanisms of grain refinement and exploit this knowledge for the benefit of industry. Among the possible modes of classification of nanostructured materials, a useful criterion is the process by which grain sizes are reduced. On this basis, two classes can be recognized: one formed by the assembly of atoms or the consolidation of nano-sized powders, and another in which conventional material is modified by hyper-deformation; techniques of the former class are able to synthetize materials having grain sizes of the order of tens of nanometers. Inert gas condensation, mechanical alloying and electro-deposition are some of these processes and, as well as the limited size that precludes practical applications, the samples which are produced may have pores and defects which make a reliable assessment of the mechanical behaviour difficult. Another process of this class - the crystallization of amorphous solids - has the advantage of producing larger and sounder samples.

The principle of the second family of processes is a severe plastic deformation (SPD), applied on conventionally cast or extruded material characterized by "normal" grain sizes, usually qualified as "coarse", to underline the contrast with those obtained after SPD processing. The five most common technologies of this class are:

- Equal Channel Angular Extrusion (ECAP)

- High Pressure Torsion (HPT)

- Accumulative roll bonding

- Cyclic close die forging

- Repetitive corrugations and straightening

The first two methods are the most common. Their functional principles and operational details were described in a recent review [1], from which it is apparent that technical cleanliness and operational simplicity are their main characteristics.

Both HPT and ECAP are capable of imparting Von Mises strains up to two figures, depending on the number of turns, passes, or die geometry. The former method can produce very small grain 
sizes; for instance, a typical HPT experiment may need pressures of up to $\approx 8 \mathrm{GPa}$, maintained during a few turns, after which grain sizes of tens of nanometers can be produced in a variety of materials. However, as mentioned before the sample dimensions severely restrict technological applications. Another setback of this technique is the absence of microstructural homogeneity as shear starts from zero at the centre of the sample and goes to a maximum at its periphery, but a solution was found simply by increasing the number of turns [2]. As for ECAP, samples are large enough to be of commercial interest and it has been demonstrated that product upscaling is perfectly viable [3]. The technique uses a die provided with two internal channels, whose main features are their intersection angle $(\Phi)$ and curvature radii (outer and inner) at this point $(\Psi)$. Presently, the most employed $\Phi$ angles are 90 or $120^{\circ}$. The former solution is preferred as it produces a more severe shear strain, whilst the second is more suitable for high strength materials such as Ti alloys and steels. Curvature radii slightly influence the imposed strain but exert a measurable effect on the reduction of pressing loads [4]. Besides the die geometrical parameters, operational variables are also quite important as it is possible to change the deformation path by applying the well known resource of interpass rotation of the sample around its long axis [1].

The effect on strength exerted by SPD has been summarized by a number of excellent reviews $[5,6]$, and it can be said that dramatic yield stress enhancement have been routinely reported. For instance, the typical yield stress of deformed (H38) coarse-grained AA3004 Al alloy is $248 \mathrm{MPa}$, but after 9 ECAP passes that figure went up to $380 \mathrm{MPa}$ [7]. In another example, a binary Al-4\%Cu showed a $300 \%$ increase in the flow stress after four ECAP passes in a $120^{\circ}$ die [8], and $250 \%$ after only two passes; this shows how readily the grain size is reduced by hyper-deformation. Recently, Zhao et al. deformed commercially pure $\mathrm{Ti}$ by the same technique using a single pass (at room temperature) and observed that flow stress increased from 405 to $680 \mathrm{MPa}$ [9]. Unfortunately, in all the above reported experiments, strength increase was accompanied by ductility loss. There are exceptions, however: a well known paper by Valiev et al. shows how by increasing the number of ECAP passes or HPT turns, in other words, increasing the deformation level, it was possible to almost recover the original ductility of commercial purity $\mathrm{Cu}$, whilst ultimate strength showed a eight-fold increase [10]. Other instances of this very sought after combination will be commented on later, but it can be said that strength and ductility optimization has become the main objective of most investigators working in the SPD field.

While HPT is still in need of a better understanding of the relationships between microstructure and operational parameters, such as pressure and number of turns, the ECAP process has been intensively studied and some examples of the main research topics are: the determination of deformation textures and the concurrent microstructural evolution $[11,12,13]$; the influence of interpass billet rotation on microstructural evolution and homogeneity [14, 15], the effect of recrystallization or recovery anneal on microstructure, mechanical properties, texture and microstructural stability [16, 17, 7], and finally how SPD affects precipitation $[18,19,20]$.

The term nanostructured is rather broad, as it encompasses dimensions between tenths to hundreds of nanometers. Thus, nanostructured materials are customarily classed as sub-microcrystalline (S-mc) and nanocrystalline $(\mathrm{nc})$, the former term qualifying policrystals with grain sizes (d) below $500 \mathrm{~nm}$ while the latter refers to materials with d close to $100 \mathrm{~nm}$ or less. The distinction is important as one of the open issues in nanostructured materials is the validity of the Hall-Petch relation, which is the basis of one of the four strengthening mechanisms. Indeed, it appears that below a certain grain size that relation is no longer valid, and it is interesting to note that the title of one of the sections of the review paper by Meyers, Mishra and Benson is "Inverse Hall-Petch relation: fact or fiction?". In this respect, Figure 15 of that paper [6] summarizes a large number of investigations correlating flow stress with grain size, over the range of $d=5-1000 \mathrm{~nm}$. This graph is reproduced here as Figure 1 and it can be clearly seen that the critical grain size for the Hall-Petch relation breakdown appears to be close to $20 \mathrm{~nm}$, meaning that S-mc material, such as that produced by ECAP, should be free from this conflict. The inverse Hall-Petch relation is logically dependent from the fact that strength cannot increase indefinitely with $\mathrm{d}^{-1 / 2}$, meaning that a critical size must exist, below which either there is no room for dislocation pile up, or the very high 
proportion of atoms associated to the boundaries introduces a resemblance to amorphous matter. Other investigators claim that the inverse Hall-Petch effect is due to flaws and other artefacts, or at most that it reduces to a change of slope of the $\sigma_{\mathrm{y}}$ against $\mathrm{d}^{-1 / 2}$ plot [6]. However, counter-examples, that is, agreement with the Hall-Petch relation, are found in the literature even for grain sizes as small as $10 \mathrm{~nm}[21,22]$.

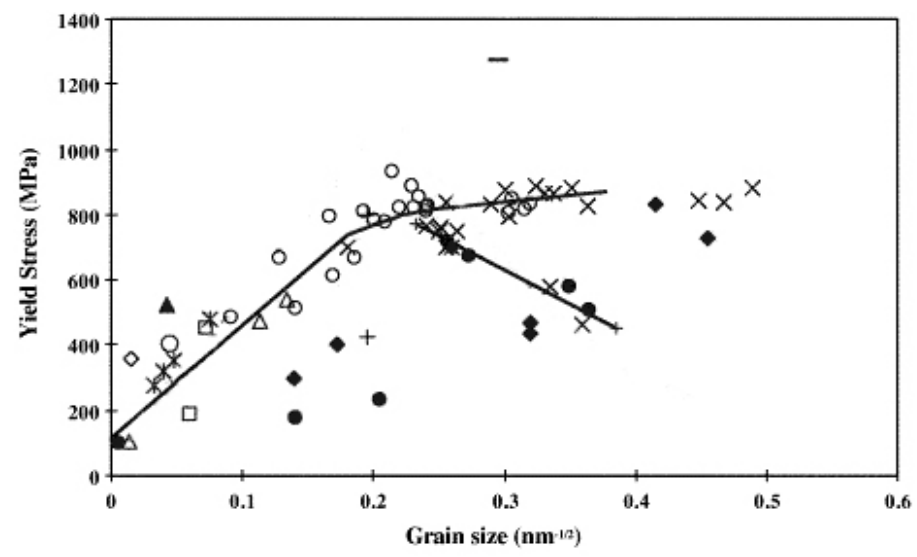

Figure 1. Compiled yield stress versus grain size plot for $\mathrm{Cu}$ from various sources ranging from coarse to nanograin size. The plots show different trends as the grain size falls below a critical size [6].

The present paper is mostly concerned with reviewing ductility mechanisms acting in S-mc Al alloys produced by ECAP. After a short review of the basic phenomena governing ductility in conventional materials, the models proposed to explain the concurrence of high strength and reasonable ductility in S-mc materials will be discussed. Only when necessary to elucidate a mecanism or concept, nc materials will be analyzed. Finally some results obtained on ECAPdeformed $\mathrm{Al}-4 \% \mathrm{Cu}$ and $\mathrm{Al}-\mathrm{Mg}-\mathrm{Mn}$ alloys (AA3004) will be presented. These experiments were designed in order to test the hypothesis that post-deformation precipitation increases work hardening (W-H), and by extension enhances ductility.

\section{Fundamentals of Ductility}

A structure must support loads, thus mechanical strength is an obvious requirement and quite often this property is among the most important criteria of any material selection event. However, it can happen that the selection procedure points to a material A which, although not excelling in strength, it does so by all other criteria when compared with material B. In this case, it is still possible to use material A by modifications of the section size and/or shape, and this can be analyzed by simply recalling the basic formula for stress acting on a beam:

$$
\sigma=\frac{\mathrm{Mc}}{\mathrm{I}}
$$

-where $\sigma$ is the stress at distance $c$, counted from the neutral axis, $M$ is the momentum acting on the beam and $I$ the second moment of inertia. Selection continues with the requirement $\sigma<\sigma_{\mathrm{y}}$ but expression (1) shows that the outcome does not depend only on the material strength but also on the cross section available to support the load. Thus, by choosing a cross section which increases the moment of inertia, material A can still be selected. On the other hand, low ductility cannot as easily be corrected by structural design; it correlates to low fracture toughness and a well known rule of thumb says that no structure is safe against catastrophic failure when the material employed has a $\mathrm{K}_{\mathrm{Ic}}$ smaller than $25 \mathrm{MPa} \mathrm{m}{ }^{1 / 2}$. Therefore, in practical terms ductility can be considered as or even more important than strength. Additionally, when the issue is formability the inability to deform plastically without tearing or fracturing is a serious drawback.

From basic metallurgy it is known that three of the four available strengthening mechanisms decrease ductility: cold deformation, precipitation and solid solution hardening. The fourth, which 
is grain size reduction, is capable of combining favourably strength and ductility, hence, the indepth research efforts directed to this hardening mechanism.

Limiting the discussion to a context of coarse (normal) grain size, the room temperature ductility of metals and alloys at low/medium strain rates, that is, $\dot{\varepsilon} \approx 1.0 \mathrm{~s}^{-1}$ is governed by a variety of factors. The most important are summarized in Figure 2 and commented on afterwards:

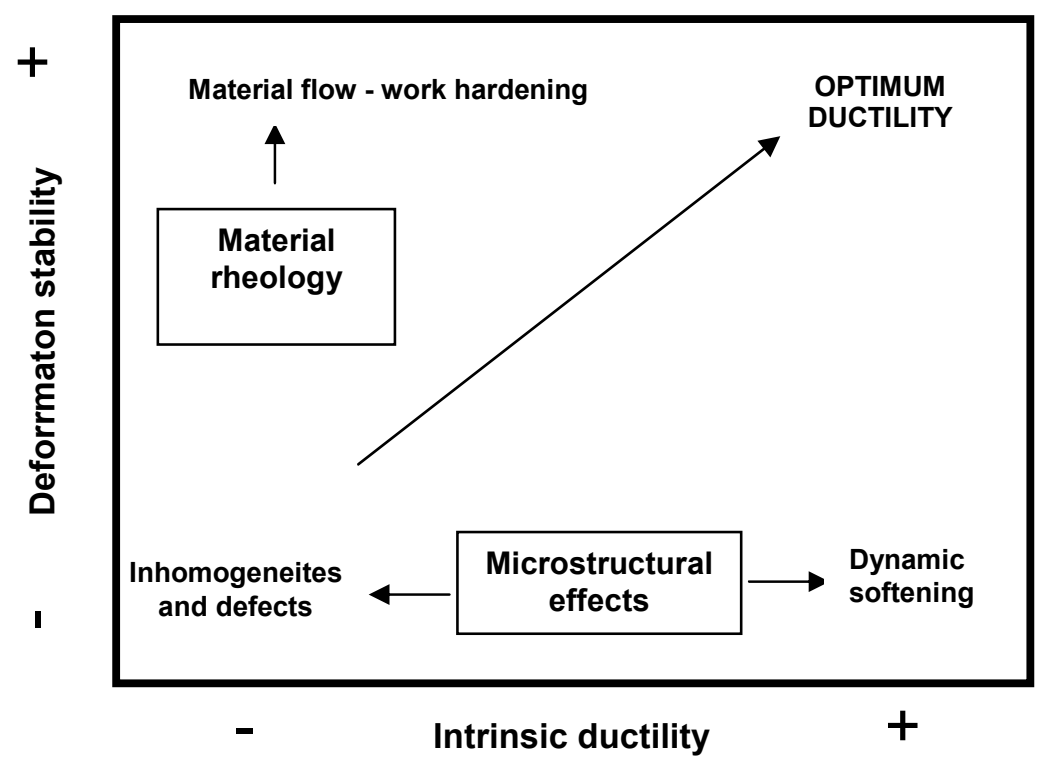

Figure 2. Main factors influencing ductility, and their respective origins and effects.

- Rheology

- Material flow: ductility, elongation and deformation homogeneity are related concepts. A tensile specimen deforming uniformly will elongate more than another in which deformation is highly concentrated. In particular, stability increases strongly with the strain hardening exponent of the Hollomon equation (n) and with the strain rate sensitivity exponent (m):

$$
\mathrm{n}=\frac{\partial \ln \sigma}{\partial \ln \varepsilon} \quad \mathrm{m}=\frac{\partial \ln \sigma}{\partial \ln \dot{\varepsilon}}
$$

These expressions describe the shape of the stress strain curve: $n$ controls before reaching the maximum stress, hence it is related to the $\mathrm{W}-\mathrm{H}$ capacity of the material, whilst $m$ acquires relevance after $\sigma_{\mathrm{y}}$, consequently it relates to the rate of necking.

Analysis of the material flow during tensile test when $\sigma=\sigma_{\mathrm{u}}$ gives the following equation for the rate of necking $\mathrm{dS} / \mathrm{dt}$, where $\mathrm{S}$ is the specimen cross section:

$$
-\frac{\mathrm{dS}}{\mathrm{dt}}=\left(\frac{\mathrm{S} \sigma}{C}\right)^{1 / \mathrm{m}} \cdot\left(\mathrm{S}^{\frac{1-\mathrm{m}}{\mathrm{m}}}\right)^{-1}
$$

The equation, which is valid when the force is constant, shows that for $\mathrm{m}=1$, the material flows in a Newtonian viscous manner and $\mathrm{dS} / \mathrm{dt}$ is independent of the cross section. In this case, the cross section rate of change will be kept constant during elongation, that is, high strain rate sensitivity limits the cross section reduction. However, when $\mathrm{m}<1$, the smaller the cross section, the faster it will decrease; in other words, deformation will concentrate more and more, leading to fast fracture with very small elongation. Summarizing, from equation (3) it is possible to judge how stable the deformation is. 
- Work-hardening: in the absence of this phenomenon, once $\sigma_{\mathrm{y}}$ is reached, the stress-strain curve would be completely flat, in other words, $\mathrm{n}=0$. However, this is rarely observed in coarse grained metals and alloys, since necking will be delayed by W-H, a phenomenon first treated by Taylor in 1934 [23]. Later, using only the average dislocation density ( $\rho)$ as a state variable, Kochs [24] described $\mathrm{W}-\mathrm{H}$ as a balance between dislocation multiplication induced by glide (A) and the annihilation of those defects (B):

$$
\frac{\mathrm{d} \sigma}{\mathrm{d} \varepsilon}=\mathrm{A}-\mathrm{B}
$$

- where A stands for $\mathrm{k}_{1} \rho^{1 / 2}$, with the constant proportional to the reciprocal of the mean free path of the moving dislocation (B will be treated when discussing dynamic recovery). This model is known as the "One parameter model" and is based on the assumption that the heterogeneity of dislocation distribution is of minor importance for the external stress required to accommodate a given strain rate. After this classic model, most of later developments are multi-parametric and the microstructure is described as composed of "soft" regions (cells interiors, with low dislocation density) and "hard" regions (cells walls). One of these multi-parametric models is due to Estrin et al. [25]; in it the storage term $\mathrm{A}$ has a linear dependence with $\rho$ and $\mathrm{k}_{1}$ has a different interpretation. More recently, Nes and Marthinsen developed a W-H model in which A can be written simply as $2 / \mathrm{bL}$, where L, the slip length, is determined solely by interactions between the mobile dislocations and the stored ones in the dislocation forest; thus, it is proportional to $\rho$ [26]. Nes and Marthinsen treatment also takes into account the influence of stacking fault energy, grain size, solid solution content, and also particle size and volume fraction. Comparison with experimental data shows that the model describes satisfactorily the $\mathrm{W}-\mathrm{H}$ behaviour of fcc metals, either pure or in the solid solution condition. Additional obstacles to dislocations mobility act mainly on the recovery rate, thus, the models which describe how they modify the overall $\mathrm{W}-\mathrm{H}$ behaviour and ductility will be dealt with in the next section.

\section{- Microstructural effects}

- Heterogeneities and microscopic defects: gas pores, shrinkage cavities, ductile microcracks and inclusions are microscopic defects leading to stress concentration and void formation. During plastic deformation, these voids grow and coalesce, thus "interrupting" the otherwise homogeneous plastic deformation. This is the classic explanation of ductile fracture and it is well known that the volume fraction of inclusion is inversely related to the value of the upper shelf Charpy curve, an indication that plastic deformation is reduced. These factors can be classified as extrinsic, since they depend on processing methods and practices.

- Dynamic softening: this effect can be thought of as the "opposite counterpart" of the dislocation accumulation and as such it must be analyzed in conjunction with this phenomenon. Dynamic softening is represented by the B term in equation (4) and acts by reducing the accumulated strain through the annihilation of dislocations of opposite signs, thus:

$$
\mathrm{B}=\mathrm{k}_{2} \rho
$$

- where $\mathrm{k}_{2}$ is the dynamic recovery coefficient, a dimensionless quantity proportional to an average annihilated dislocation length when an annihilation event takes place. The term B depends of temperature, strain rate and solute concentration. The Kochs [24] and Estrin [25] models differ in terms of the meaning of $\mathrm{k}_{2}$. In the former, this parameter is proportional to an average annihilated dislocation length, whilst in the latter $\mathrm{k}_{2}=\mathrm{L} / \mathrm{b}$, where $\mathrm{L}$ represents the critical dipole separation, dipoles being the result of interactions between mobile and stored dislocations. Finally, in the Nes and Marthinsen model, the dipole annihilation reaction figures as the controlling mechanism [26]; there, in its simpler form B expresses the stability of the cell-interior dislocations in terms of 
network growth and the sub-boundary structure in terms of subgrain growth. Analytically, B is the product of $\rho$ with a term standing for the dislocation annihilation frequency, divided by the strain rate.

Recovery is typical of metals of high stacking fault energy; it relies on extensive dislocation climb and cross slip, it is thermally activated but can also occur at room temperature for very high deformation levels. It is favoured by small grain sizes, to such an extent that for nanostructured materials it dominates equation (4) and a small $\mathrm{W}-\mathrm{H}$ is observed. A second mechanism for softening is recrystallization, favoured by metals of low stacking fault energy but ultimately it takes place in all kind of metals if the deformation and/or annealing temperature are sufficiently high. However, mechanical strength is drastically reduced, thus this phenomenon has to be avoided if some of the strength obtained by SPD has to be maintained. Finally, high strain rate inhibits dynamic recovery and recrystallization.

When dealing with alloys, two situations must be considered: (i) solid solution - W-H is modified by changes in stacking fault energy or solute drag effects on dislocations; (ii) second phase particles - their effect on W-H was originally treated by Ashby [27] and developed by Estrin [28]; in this model the storage of dislocations around particles is relevant only for non-shearable precipitates due to their capacity to store dislocation loops. These loops may rearrange, thus increasing the global storage rate for dislocation; moreover, the non-deformable particles increase the local elastic stresses. Taking into account these contributions, equation (4) can be rewritten as:

$$
\frac{d \sigma}{d \varepsilon}=A-f B+C
$$

- where $\mathrm{f}$ is a modifying factor due to the effect of precipitate/dislocation interactions on dynamic recovery and $C$ stands for the storage of geometrically necessary dislocations due to the nonshearable particles. The phenomenon is quite complicated: for instance, as recently shown by Faseli et al., precipitation causes solute depletion of the matrix, an event that may affect dynamic recovery through stacking fault energy change [29]. Their paper also reports on experiments performed on a AA3004 alloy in which the $\mathrm{W}-\mathrm{H}$ behaviour depends on the ratio $\mathrm{f}_{\mathrm{s}}$ (volume fraction)/ $\mathrm{r}$ (average radius) of the non-shearable precipitates. The fact that the $\mathrm{Mg}$ content does not change throughout these experiments allowed the separate analysis of each of the three contributions to $\mathrm{W}-\mathrm{H}$ : solid solution, shearable, and non-shearable precipitates. In a similar investigation, Esmaeili et al. concluded that finely dispersed $\beta$ " precipitates in an AA611 alloy increased W-H [30]. More recently, analogous findings were obtained in a 2024 alloy with a grain size between 0.4 and $1.5 \mu \mathrm{m}$ [31]. Finally, Deschamps and collaborators presented very clear evidence that in peak aged conditions, when precipitates are presumably of the shearable type, $\mathrm{W}-\mathrm{H}$ is less intense and its value quickly decreases to the normal value of $\mu / 20$, where $\mu$ is the shear modulus [32]. After peak aging precipitates are shearable and the initial $\mathrm{W}-\mathrm{H}$ increases significantly. This investigation was performed on the AA7000 (Al-Zn-Mg) and AA6000 (Al-Mg-Si-Cu) systems, and on a Fe-Cu alloy.

For the solid solution condition Rollet et al. have observed a strong positive effect on the W-H capacity [33]; however, as observed by Deschamps and collaborators in precipitation hardening alloys, the phenomenon is limited to the initial stages of straining and is due to dynamic precipitation during straining [32].

\section{Ductility of Sub - Microcrystalline Materials}

Since the present discussion is limited to materials produced by ECAP, issues such as flaws and pores are ruled out. However, it will be seen that depending on the raw material preparation technique, internal defects can play a role in ductility, at least at the initial stages of processing.

$\mathrm{S}-\mathrm{mc}$ and nc materials have a very high proportion of atoms associated with the grain boundaries, a feature that decreases intragranular-mediated plasticity and explains their low ductility. It follows that alternative plasticity mechanisms must be activated, most of which are related to the grain 
boundaries. Moreover, in the particular case of SPD materials, residual stresses and dislocation locking are additional factors limiting ductility.

As mentioned in the Introduction, although low ductility is one of the main drawbacks of nanostructured materials, some instances of ductile behaviour have been reported $[34,35,36]$, and the search for an explanation has led to the study of the following candidate mechanisms:

- Grain boundary sliding

- Grain boundary rotation

- Non-equilibrium grain boundaries

- Bimodal grain size distribution

- Second phase precipitates

The first two mechanisms are often mentioned in connection with proper nc materials; indeed, Meyer et al. point out that grain boundary sliding occurs and is dominant for $d<10 \mathrm{~nm}$ [6], a conclusion supported by molecular dynamic computer simulation, always invariably directed to the nc range [34, 35]. However, this mechanism has also been considered as probable in a number of cases in which grain size was in the S-mc/coarse range. For instance, Ma et al. [36] produced evidence of ductility enhancement of an $\mathrm{Al}-11 \% \mathrm{Si}$ alloy processed by rotary ECAP, see Charpy data reproduced in Figure 3. The effect is remarkable and in a companion paper, the authors attributed it to grain boundary sliding [37], but it is more probable that the refinement of the primary silicon particles was the dominant cause. More direct evidence of grain boundary sliding at room temperature was recently obtained in high purity aluminium (99.99\%), which after 8 ECAP passes showed a relatively large grain size, that is, $1.2 \mu \mathrm{m}$ [38]. By comparing the surface rumpling around depth-sensing indentation marks, it was estimated that the contribution of grain boundary sliding to the total deformation was in the $40-70 \%$ range. More recently Sabirov et al. attributed the significant increase of uniform elongation of a AA6063 Al alloy to grain boundary sliding, when the strain rate is reduced [39].

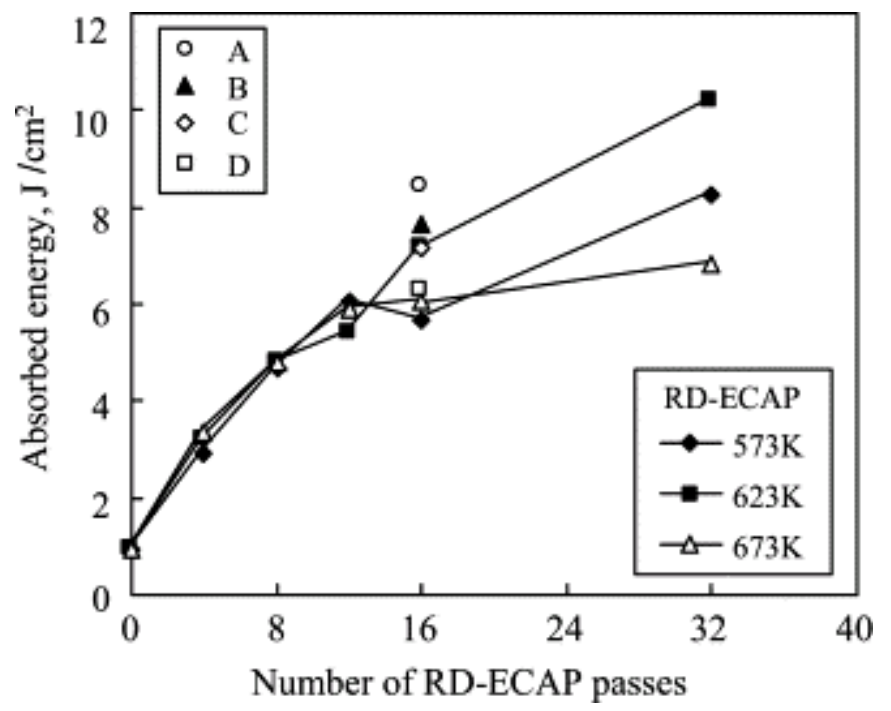

Figure 3. The absorbed energy of the samples as a function of the number of RD-ECAP passes at 573, 623, $673 \mathrm{~K}$ and other routes: (A) at $673 \mathrm{~K}$ for 8 passes followed 8 passes at $623 \mathrm{~K}$; (B) at $673 \mathrm{~K}$ for 4 passes followed by 12 passes at $623 \mathrm{~K}$; (C) at $573 \mathrm{~K}$ for 4 passes followed by 4 passes at $673 \mathrm{~K}$ then 8 passes at $623 \mathrm{~K}$; (D) at $673 \mathrm{~K}$ for 4 passes followed by 4 passes at $623 \mathrm{~K}$ then 8 passes at $573 \mathrm{~K}$ [36].

Overall, the experimental evidence mentioned above, all obtained in materials submitted to SPD, appears to disagree with one of the main conclusions of a comprehensive review paper on deformation behaviour of nc materials [40]. According to it, S-mc materials still seem to deform by the conventional dislocation-slip mechanism - the grain boundaries acting as dislocation sources for the nucleation of dislocations that subsequently glide across the grains where they become reincorporated into the boundary structure. It concludes that the main difference between S-mc and coarse - grained materials resides in the inability of Frank-Read sources to operate within the small grains. However, the number of recent investigations in S-mc materials pointing out to grain boundary sliding as an operative mechanism appears to be growing; for instance internal friction 
measurement was performed on a variety of materials: a TiNi intermetallic, commercially pure Ti, Ti-Al-4V and an Al-Mg-Li alloy [41]. Data on Ti are more complete and refer to samples with coarse grains $(10 \mu \mathrm{m})$ and S-mc grains (ECAP, $300 \mathrm{~nm}$ and ECAP plus rolling, $150 \mathrm{~nm}$ ). The authors show that grain size reduction led to a decrease in grain boundary diffusion activation energy, thus shifting the onset of grain boundary sliding to lower temperatures. Furthermore, the reduction of grain boundary perfection reduces the local diffusional activation energy as well, a trend observed in all the materials investigated.

The relationship between grain boundary sliding and grain boundary character gives scope to some comments on non-equilibrium grain boundaries and their role on the ductilization of SPD materials. In this respect, the importance of the nature of grain boundaries is self evident as S-mc and coarse-grained materials are compared in terms of boundary area. It must also been taken into account that plastic flow initiates at the boundaries because the maximum shear stress at these sites is between two and three times the maximum stress in homogeneous materials [42]. A very complete treatment of grain boundary structure in general, and of non-equilibrium boundaries in particular, is by Valiev and collaborators, who defined the latter as those boundaries characterized by a high density of extrinsic dislocations, that is, those which are additional to the geometrically necessary dislocations [43]. This excess density of line defects leads to the establishment of elastic strains, which extend well into the neighbouring grains. Finally, transmission electron microscopy observations by Huang et al. were quite successful in characterizing non-equilibrium boundaries and other microstructural features formed during SPD [44]. Furthermore, a link between ductility and non-equilibrium boundaries was shown in a short review paper by Ma who named a section of that paper as Strategies to derive good ductility from nanostructures [45]. According to the author, the excess dislocations promote slip and can even enable grains to slip or rotate.

Non-equilibrium boundaries tend to be wavy and show spreading of the so-called thickness extinction contours, a feature indicative of a high level of elastic stresses and crystal lattice distortions near the grain boundaries [46]. Finally, recalling that grain boundary sliding in superplasticity depends on the grain boundary diffusion coefficients $\left(\mathrm{D}_{\mathrm{gb}}\right)$, it is interesting to know whether: (i) there is any relationship between $D_{g b}$ and the nature of the boundary; (ii) a high $D_{g b}$ enhances low temperature boundary sliding. Two recent investigations answer positively to the first question [47, 48]; in one of those, Al-Zn and Al-Mg alloys were ECAP-deformed in such a way that different fractions of high angle and low angle boundaries were produced. Kinetic measurement on diffusion couples showed that $\mathrm{Mg}$ and $\mathrm{Zn}$ interdiffusion are faster along non-equilibrium boundaries. Same conclusion was reached by the other investigation, by measuring the penetration profile of radioactive $\mathrm{Ni}$ in $\mathrm{S}-\mathrm{mc}$ pure $\mathrm{Cu}$. However, the relationship between $\mathrm{D}_{\mathrm{gb}}$ and boundary sliding is still an open issue.

The next strategy to be discussed here is the production of a bimodal grain size distribution. For non-ferrous metals or alloys such feature can be obtained by hot/warm ECAP pressing, by purposely designed post-deformation heat treatments, or alternatively by SPD consolidation of particles belonging to two size classes [49]. In all cases the resulting microstructures combine high strength and good ductility, the former a characteristic of the nc or S-mc grains and the latter a consequence of the high W-H capacity of the larger grains. In a series of papers, Lavernia and collaborators proposed a mechanism to explain ductility enhancement in an ECAP-deformed 5083 Al alloy $[50,51]$. According to the model, cracks follow a fast, intergranular path when running through the nanostructured grains, but are blunted and slowed down when they encounter a large and soft grain. Results also show that the W-H rate increases moderately with the volume fraction of large grains, and the correspondent increase in ductility is reflected almost completely in the total strain, leaving the uniform elongation unchanged [51]. On the other hand, a particularly successful example of this strategy was observed in pure $\mathrm{Cu}$ submitted to a thermomechanical treatment from which a mixture of $75 \% \mathrm{~S}-\mathrm{mc}(<200 \mathrm{~nm})$ and $25 \%$ larger grains $(1-3 \mu \mathrm{m})$ was obtained [52]. The uniform elongation increased from 5 to $30 \%$ without appreciable strength loss. A volume fraction of approximately one quarter of large grains should be harmful to strength but twinning of the large grains, a feature which is known to enhance W-H, must have contributed to limit the strength loss. 
However, in some other instances results are fairly modest [53, 54], suggesting that the bimodal grain size distribution strategy is difficult to control, in other words, it has a narrow process window.

Finally, the last ductility-enhancing resource that will be here reviewed is based on the effect of second phase precipitates, a feature which, as discussed earlier in the context of coarse grained materials, acts mainly on the W-H capacity of the material. This resource has the advantage of exploiting mechanisms which are typical of commercial alloys, thus directing investigators to the study of these useful materials. Altogether, two different approaches can be recognized: (i) alloys with pre-existing precipitates are submitted to SPD; (ii) precipitation heat treatment follows SPD. In the former, particles are fractured by the intense shear, forming a finer dispersion, and in many investigations dissolution of these debris is mentioned [55, 19]. For instance, natural aging, followed by ECAP and artificial aging were applied to a AlZnMg alloy [56]. It was found that for very short pre-deformation aging times (practically solid solution condition) strength could be increased with only one or two passes. This has obvious practical advantages, but the reason behind this behaviour is still poorly understood; however, TEM observation showed that a possibility worth studying is the control exerted on the shear bands thickness by acting on the extent of natural aging.

In the post-ECAP precipitation approach the second phase nucleation rate is enhanced by the dislocation substructure [57] and, if the heat treatment is performed at a sufficiently low temperature, the effects of SPD on the strength are maintained. A thorough investigation, focusing on ductility improvement by this method was carried out by Cheng et al. on a commercial AA2024 alloy which was cryo-rolled and subsequently aged at 100 and $160^{\circ} \mathrm{C}$ for different lengths of time [31]. Results show that the lower temperature precipitation heat treatment produced a good combination of strength and ductility, see Figure 4 , with elongation increasing by $\approx 300 \%$ with respect to the as-deformed material. The result was attributed to dislocation accumulation around relatively large dispersoids combined with an increase of $\mathrm{W}-\mathrm{H}$ rate. The latter effect was caused by that same mechanism, promoted by the nano-sized high volume fraction precipitates (10 to $15 \mathrm{~nm}$; $\approx 4 \times 10^{15} \mathrm{~m}^{-2}$ ) produced by the $100^{\circ} \mathrm{C}$ heat treatment. Indeed, a Kochs-Mecking plot showed a higher $\mathrm{W}-\mathrm{H}$ rate than the obtained by the $160^{\circ} \mathrm{C}$ heat treatment (particle size and volume fraction equal to $\approx 30 \mathrm{~nm}$ and $1 \times 10^{15} \mathrm{~m}^{-2}$ ). Overall, the combined effects of precipitation hardening, dislocation recovery and grain size should be sufficient to explain the results; thus strength increase indicates predominance of the first mechanism whilst enhanced ductility is a consequence of the predominance of the second. The authors do not explain the ductility (and strength) drop observed after $\approx 15 \mathrm{~h}$ at $160^{\circ} \mathrm{C}$. More importantly, the increase in $\mathrm{W}-\mathrm{H}$ capacity is attributed solely to the high density of nanosized precipitates produced at $100^{\circ} \mathrm{C}$. However, the association non-shearable precipitates/high W-H rate, which was validated for coarse grain size systems [28, 30, 32] was not mentioned or tested. At any rate, the establishment of a sharp shearable/non-shearable transition is quite difficult; Esmaeili et al. assume that the transition occurs at an overaged condition [58] and an investigation performed on coarse-grained AA6111 proposed that it would be indicated by a sharp change in magnitude of $\mathrm{W}-\mathrm{H}$ rate [59]. 

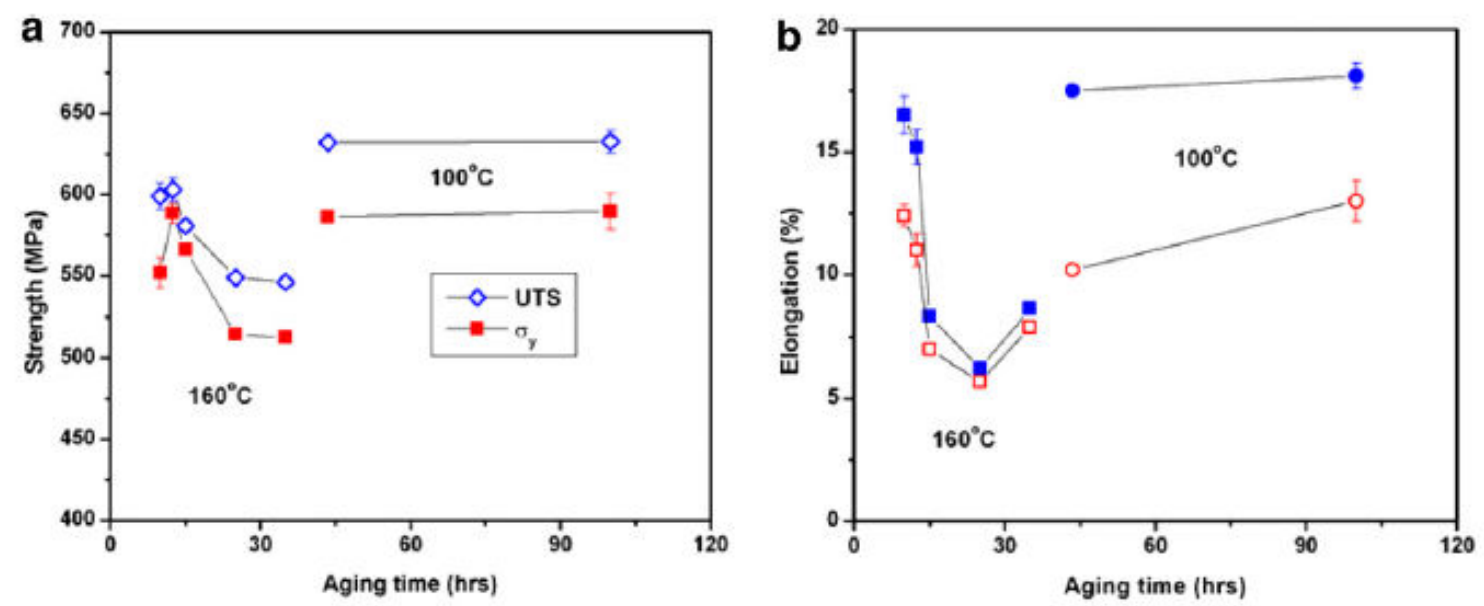

Fig. 4. Tensile strength variations with aging time at 160 and $100^{\circ} \mathrm{C}$ (a). For samples aged at $160^{\circ} \mathrm{C}$, both the yield strength and the UTS reach a peak at $\mathrm{t}=13 \mathrm{~h}$, then decrease with longer aging times. For samples aged at $100^{\circ} \mathrm{C}$, the yield strength and UTS stayed nearly unchanged from $\mathrm{t}=42$ $\mathrm{h}$ to $\mathrm{t}=100 \mathrm{~h}$. (b) Tensile elongation-to-failure (solid symbols) and uniform elongation (open symbols) variations with aging time at 160 and $100^{\circ} \mathrm{C}$, respectively [31].

Other investigations show conflicting results; for instance, a commercial AA2024 Al alloy in the solid solution condition was ECAP-deformed ( 1 pass only) and aged at $100^{\circ} \mathrm{C}$ for 10,20 and 30 $\mathrm{h}[60]$. Besides a large yield stress increase over the $\mathrm{T}-351$ heat treated alloy $(+33 \%)$, no improvement on uniform elongation was observed, although total elongation showed a definite advantage over the ECAPed-deformed, non-aged sample (18 against 10\%). Finally, Okashi et al. reported a similar behaviour in Al-10.8\%Ag alloy also submitted to ECAP and subsequently aged at 100 and $200^{\circ} \mathrm{C}$ [61]. Microhardness measurements clearly show the interaction of static recovery and precipitation hardening, the former phenomenon dominating the $200^{\circ} \mathrm{C}$ aged samples and the latter those aged at $100^{\circ} \mathrm{C}$. Only the low temperature-aged group of samples was submitted to tensile tests and while there was a negligible benefit on strength, a definite improvement of uniform elongation was observed. The small effect on strength reflects the fact that grain boundary precipitation decreased the solute supersaturation, hence the volume fraction of intragranular precipitates.

\section{Ductility, Microstructure and Work - Hardening. Experiments}

In this section, some experimental results obtained in two systems are presented: a commercial Al-Mn-Mg alloy produced by Hydro Aluminium (AA3004), and a laboratory-cast Al-4\%Cu alloy, representing non-heat treatable and heat treatable alloys, respectively. The main objective of the investigation was to characterize and discuss the relationship between W-H behaviour and microstructure. The microstructural variables or conditions were: (i) as ECAP-deformed samples; (ii) same, plus precipitation heat treatments, and (iii) same, plus annealing heat treatments. Figure 5 is a flow sheet of the experimental procedure and of the samples identification scheme. Conventional extrusion preceded the experimental steps illustrated in this figure. 


\section{Experimental procedure}

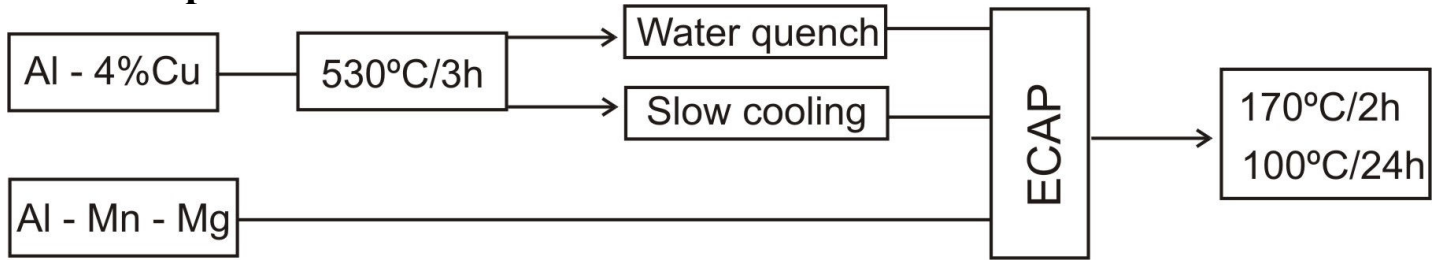

$\mathrm{nX}=\mathrm{n}$ is the number of passes

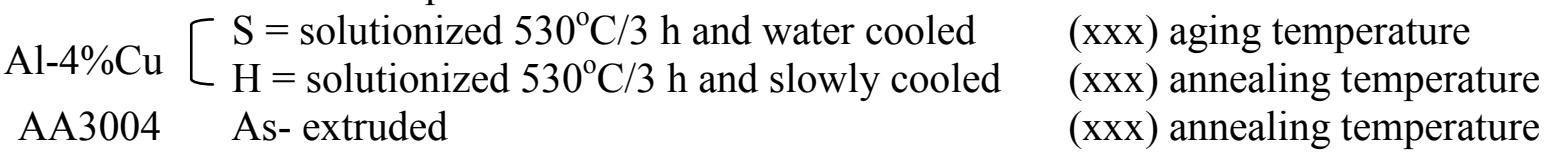

Figure 5. Flow sheet of the experimental procedure and scheme of sample identification.

Deformation: conducted at room temperature in an ECAP die with $\Phi=120^{\circ}$ and $\Psi=0^{\circ}$ (inner and outer radii of curvature equal to $8 \mathrm{~mm}$ ) according to route A. Specimens were subject to one and to four passes.

Characterization: sub-sized tensile specimens (12 $\mathrm{mm}^{2}$ section, $19 \mathrm{~mm}$ gauge length) were tested at $10^{-3} \mathrm{~s}^{-1}$ using an INSTRON machine Mod 5500R. Observations by transmission electron microscopy (TEM) and selected area electron diffraction (SAED) were carried out in a Phillips CM 120 electron microscope. Foils were prepared by polishing $3 \mathrm{~mm}$ diameter discs until perforation in a TENUPOL 3 equipment and the electrolytic solution consisted of a 7:3 solution of methanol/nitric acid.

\section{Tensile behaviour}

True stress true strain curves for the two systems under various conditions are in Figure 7 and the respective quantitative data are summarized in Table 1. It is apparent that besides having a higher strength, the Al-4\%Cu shows a more accentuated $\mathrm{W}-\mathrm{H}$ behaviour than the AA3004 alloy.

- Al-4\% $\mathrm{Cu}$ alloy: the post-deformation heat treatment of samples $\mathrm{S}$ has two opposite effects: precipitation hardening and static recovery. Therefore, identical thermal cycles were applied to the $\mathrm{H}$ series, characterized by a coarse dispersion of $\mathrm{Al}_{2} \mathrm{Cu}$ particles, with no hardening effect and relative absence of $\mathrm{Cu}$ in solid solution.

- AA3004 alloy: the post-deformation thermal cycles have the sole purpose of providing a direct comparison with the $\mathrm{Al}-4 \% \mathrm{Cu}$ alloy, i.e. they exert an annealing effect.
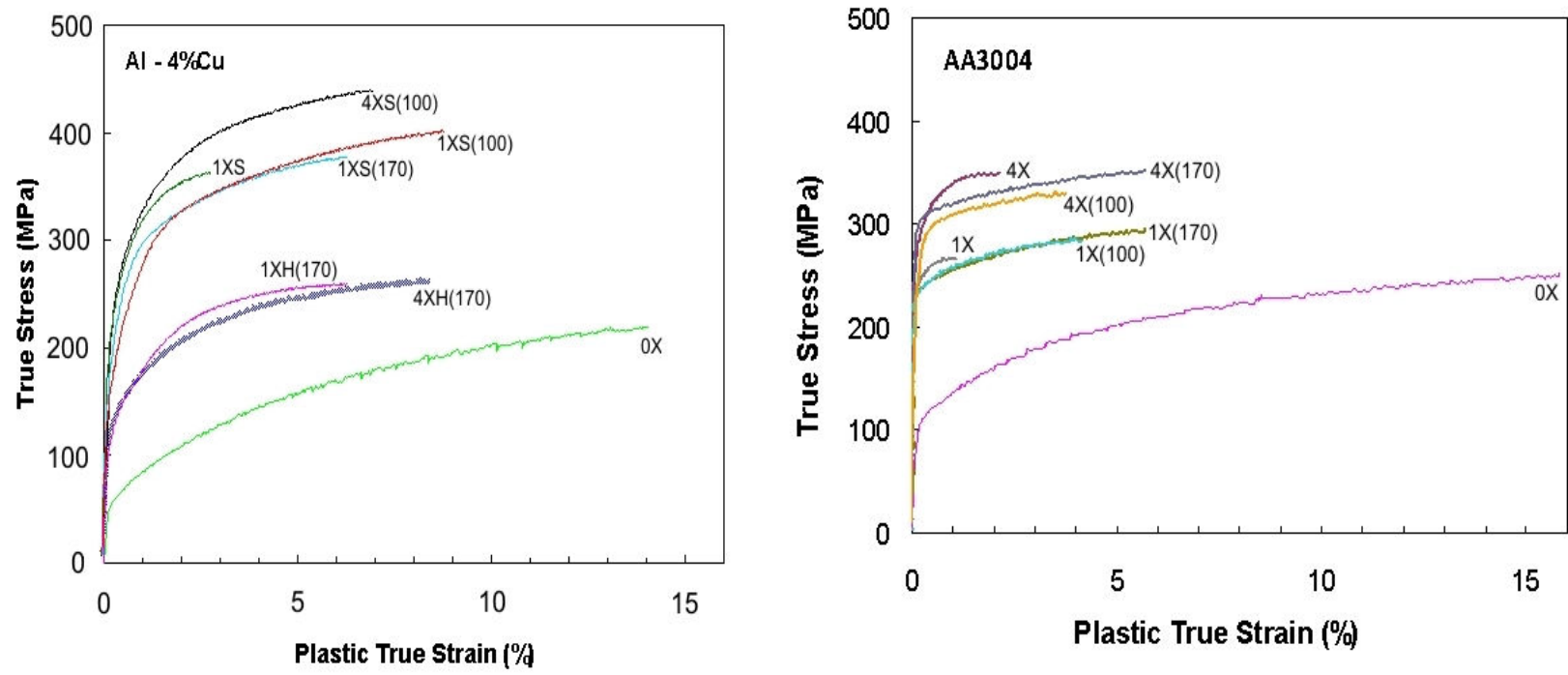

Figure 7. True stress-true strain curves of ECAP-deformed and heat treated Al-4\%Cu and AA3004 alloys. 
Table 1. Tensile properties and strain hardening exponent of ECAP-deformed and heat treated $\mathrm{Al}-4 \% \mathrm{Cu}$ and $\mathrm{AA} 3004$ alloys

\begin{tabular}{|c|c|c|c|c|c|c|}
\hline Alloy & Sample & $\sigma_{\mathrm{y}}(\mathrm{MPa})$ & $\sigma_{\text {uts }}(\mathrm{MPa})$ & $\varepsilon_{\text {unif }}(\%)$ & $\varepsilon_{\text {total }}(\%)$ & $\mathrm{n}$ \\
\hline \multirow{7}{*}{ 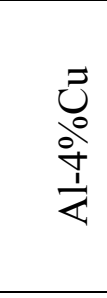 } & $0 \mathrm{X}(* *)$ & 75 & 220 & 14 & 20 & \\
\hline & $1 \mathrm{XS}$ & 254 & 354 & 2.8 & 6.2 & 0.22 \\
\hline & 1XS (170) & 220 & 356 & 6.3 & 13 & 0.28 \\
\hline & 1XS (100) & 196 & 368 & 8.7 & 15 & 0.32 \\
\hline & 4XS (100) & 291 & 413 & 7.0 & 12 & 0.20 \\
\hline & 1XH170 & 157 & 260 & 6.3 & 17 & 0.22 \\
\hline & $4 \mathrm{XH170}$ & 157 & 265 & 8.4 & 12 & 0.20 \\
\hline \multirow{8}{*}{ 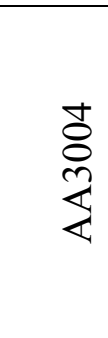 } & $0 \mathrm{X}(\mathrm{H} 38)^{*}$ & 250 & 285 & - & $4-6$ & - \\
\hline & $0 X^{* *}$ & 114 & 252 & 17 & 32 & \\
\hline & $1 \mathrm{X}$ & 240 & 264 & 1.1 & 20 & 0.10 \\
\hline & $1 \mathrm{X}(170)$ & 220 & 276 & 5.7 & 21 & 0.12 \\
\hline & $1 \mathrm{X}(100)$ & 237 & 272 & 4.1 & 18 & 0.11 \\
\hline & $4 \mathrm{X}$ & 280 & 341 & 2.1 & 17 & 0.07 \\
\hline & $4 \mathrm{X}(170)$ & 300 & 331 & 5.7 & 20 & 0.07 \\
\hline & $4 \mathrm{X}(100)$ & 280 & 316 & 3.8 & 15 & 0.08 \\
\hline
\end{tabular}

From the above data, it can be observed that strength increases with the number of passes, and ductility with post-deformation aging (or annealing, for alloys AA3004 and Al-4\%Cu H group). Furthermore, the strain hardening exponent is much larger for the binary alloy. A feature of the AA3004 series is the fact that total elongation is much larger than uniform elongation, suggesting a high strain rate sensitivity $m$. Within the data on $\mathrm{Al}-4 \% \mathrm{Cu}$, two groups of samples can be recognized: those submitted to the precipitation treatments ( $\mathrm{S}(\mathrm{xxx})$ group), characterized by high strength and high uniform ductility, and the slowly cooled and annealed specimens ( $\mathrm{H}$ group), with lower strength but comparable ductility. As for the AA3004 alloy, both strength and elongation after ECAP are much higher that those of its cold rolled (H38) counterpart, see comparison in Table 1.

In Figure 8 the $\mathrm{W}-\mathrm{H}$ behaviour is expressed by Kocks-Mecking plots (K-M). Again it is apparent that the $\mathrm{W}-\mathrm{H}$ rate is much larger for the $\mathrm{Al}-4 \% \mathrm{Cu}$ alloy than for the AA3004. From these plots, two operational parameters can be defined: (i) $\theta_{\max }$, or the maximum W-H rate, and (ii) $d \theta / d \sigma$, which is the slope of the K-M curve. The physical meaning of these parameters can be found by recalling expression (4): $\theta_{\max }$ is proportional to $\mathrm{A}$, in other words it is a measure of the dislocation accumulation, whilst $d \theta / d \sigma$ can be shown [60] to be related to $B$, thus is proportional to the dynamic recovery rate. A number of comments can be made on the tensile and W-H data:

(i) There is a linear relationship between $(\theta)_{\max }$ and $\mathrm{d} \theta / \mathrm{d} \sigma$, meaning that dislocation accumulation and recovery rate are concurrent mechanisms. This is what would be expected, since in the above mentioned expression, the dislocation density appears in the A and in the B factors; (ii) Stage III is well developed in the majority of the samples; (iii) Stage IV is absent in all samples in the asdeformed condition (iv) Post-deformation aging increases both strength and elongation in the Al-4\% Cu alloy; (v) For the AA3004 alloy the post-deformation thermal cycles act as annealing heat treatment: strength is almost unchanged but ductility increases dramatically. 

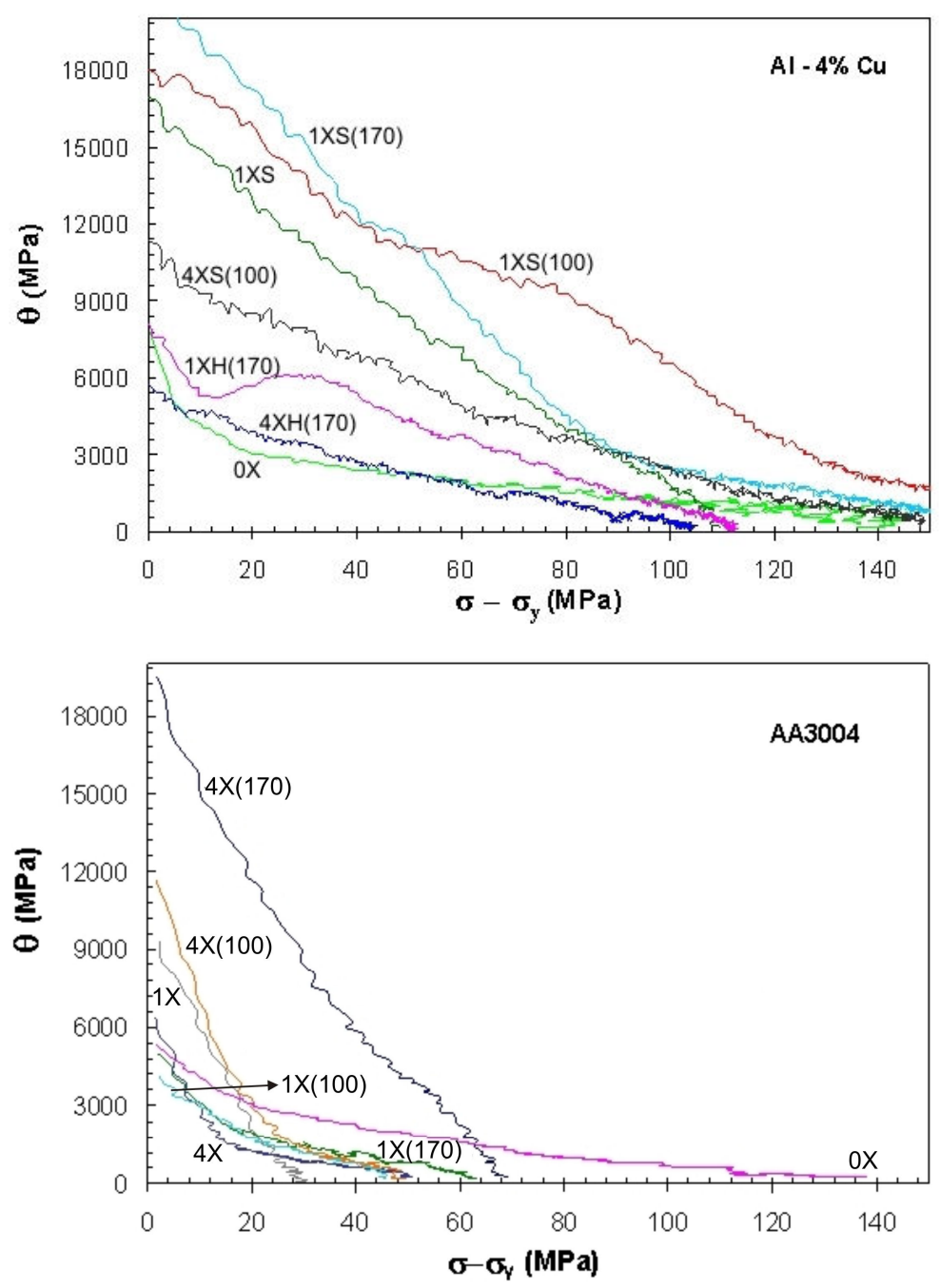

Figure 8. Kocks-Mecking plots for the $\mathrm{Al}-4 \% \mathrm{Cu}$ and $\mathrm{AA} 3004$ alloys

The main question underlying the experiments here reported is how to relate $\mathrm{W}-\mathrm{H}$ behaviour with the material microstructure in order to select the optimum metallurgical practice. Figure 9 shows plots of $\mathrm{d} \theta / \mathrm{d} \sigma$ versus uniform elongation for the two alloys: the analysis of these curves will be made further on in connexion with the microstructure, See Figure10.
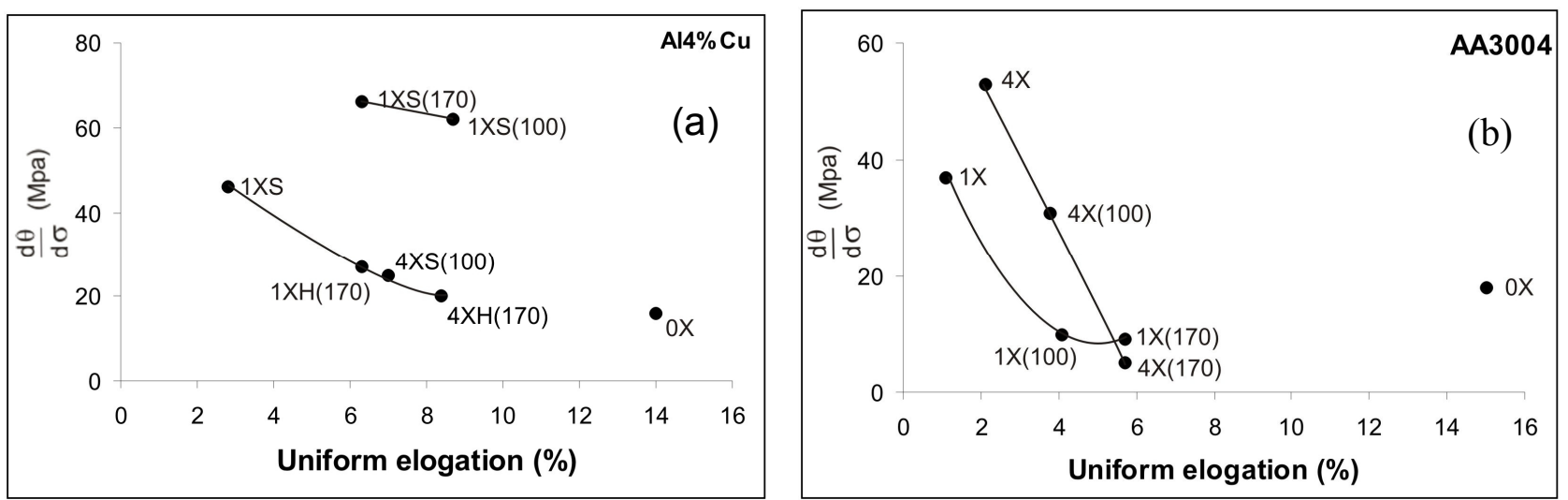

Figure 9. Correlation between the uniform elongation and $d \theta / d \sigma$, a parameter obtained from the $\mathrm{K}-\mathrm{M}$ plots and expressing the rate of dynamic recovery of the: (a) Al-4\%Cu and (b) AA3004 alloys. 


\section{Microstructural development}

The first two micrographs of Figure 10 show typical features of the $\mathrm{Al}-4 \% \mathrm{Cu}$ alloy; in (a), the
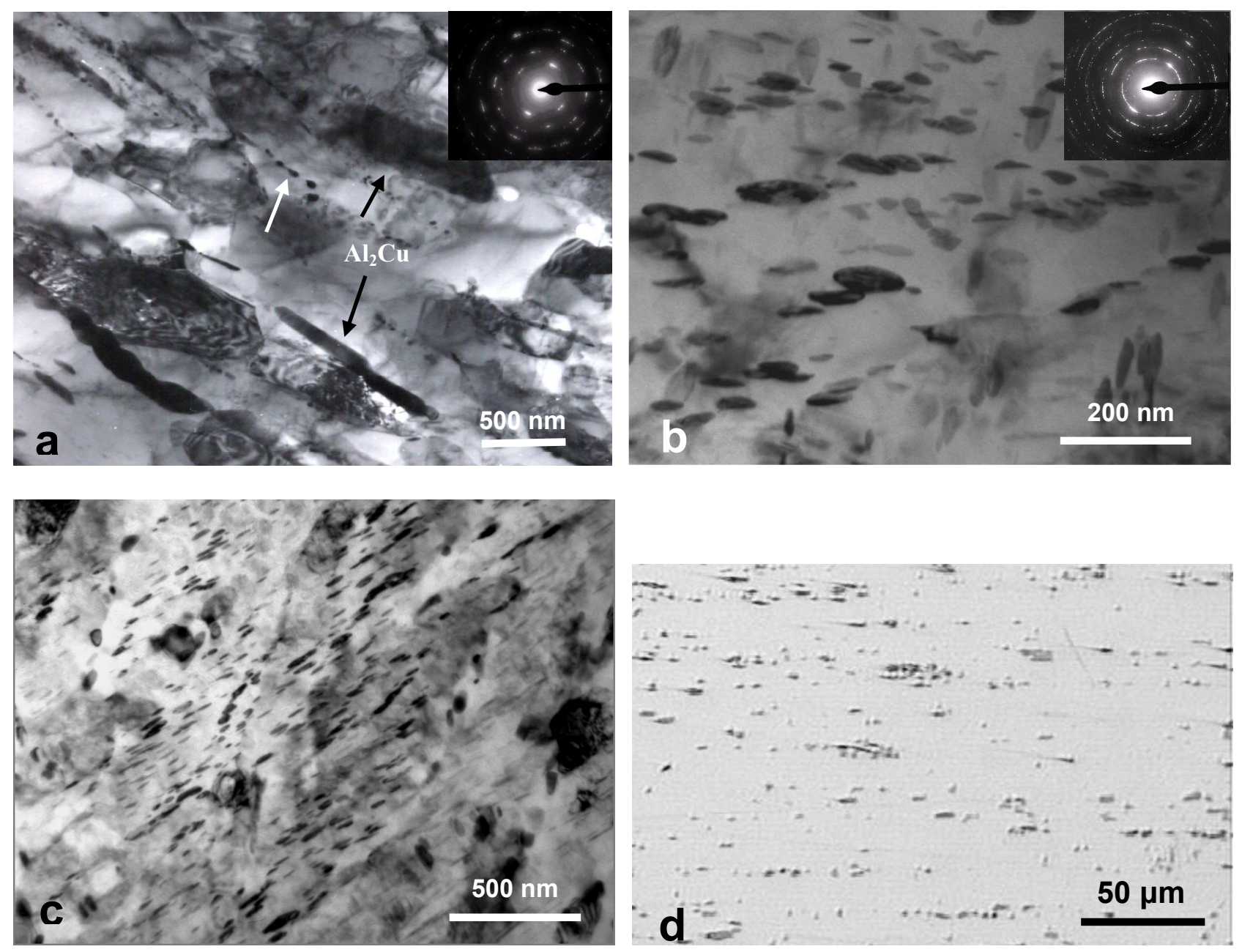

Figure 10. TEM micrographs of (a) slowly cooled, 1XH sample; (b) water quenched, ECAPdeformed with four passes and aged at $100^{\circ} \mathrm{C} / 24 \mathrm{~h}$, and (c) same but aged at $170^{\circ} \mathrm{C} / 2 \mathrm{~h}$. The optical micrograph (d) shows the initial (conventionally extruded) microstructure of the AA3004 alloy.

sample was slowly cooled from the homogenizing temperature and in (b) it was solution heat treated, water cooled, ECAP-deformed and aged at $100^{\circ} \mathrm{C} / 24 \mathrm{~h}$. In the former condition, precipitation occurred during cooling from the homogenizing temperature; thus the particles are quite large $(\approx 0.5 \mu \mathrm{m}$ or more) and located preferentially along sub-grain boundaries, with some evidence of fracturing. In the second condition, a much higher volume fraction of more evenly distributed $\mathrm{Al}_{2} \mathrm{Cu}$ particles is clearly seen, although boundaries are still decorated by precipitates. Comparison of the diffraction patterns shows that the proportion of high angle boundaries increases with deformation and with post-ECAP heat treatment. Micrograph (c) and (d) show respectively sample 4XS(170) and a longitudinal section of the conventionally extruded alloy AA3004. The sample shows particles, aligned by that process, identified by EDS microanalysis as corresponding to the $\mathrm{Al}_{12}(\mathrm{Fe}, \mathrm{Mn})$ intermetallic. Finally, Table 2 summarizes precipitate and grain size data. 
Table 2. Summary of grain and precipitate sizes

\begin{tabular}{lccc}
\hline Sample & $\begin{array}{c}\text { Precipitation } \\
\text { temperature }\left({ }^{\circ} \mathrm{C}\right)\end{array}$ & $\begin{array}{c}\text { Grain size } \\
(\mathrm{nm})\end{array}$ & $\begin{array}{c}\mathrm{Al}_{2} \mathrm{Cu} \text { particles } \\
\text { length }(\mathrm{nm})\end{array}$ \\
\hline $0 \mathrm{X}$ & - & 30000 & - \\
$1 \mathrm{XS}$ & 170 & $\mathrm{NM}$ & $34 \pm 1$ \\
& 100 & $\mathrm{NM}$ & $9.4 \pm 0.4$ \\
$4 \mathrm{XS}$ & 170 & 200 & $30 \pm 1$ \\
& 100 & $\mathrm{NM}$ & $20 \pm 1$ \\
\hline
\end{tabular}

$\mathrm{NM}=$ non measurable

It is now possible to analyze the relationship between uniform elongation and $\mathrm{W}-\mathrm{H}$ rate, summarized by Figure 9. Beginning with the Al-4\% Cu alloy, the comments are as follows: (i) Postdeformation aging ( $\mathrm{S}$ group) or annealing (H group) lead to different dynamic recovery rates when compared with the non-deformed (0X) and solid solution (1XS) samples; (ii) It is difficult to isolate and assess the effect of precipitation, since the overall behaviour is governed by the combined action of deformation level (1X or $4 \mathrm{X}$ ), by the level of $\mathrm{Cu}$ in solid solution, and by the precipitate distribution (homogeneity), size and volume fraction; (iii) Precipitation causes a discernible effect on strength, see differences between the $\mathrm{S}$ and $\mathrm{H}$ series of samples; (ii) The reason why samples $1 \mathrm{XS}(\mathrm{xxx})$ show a higher recovery rate may be related to their lower dislocation saturation, meaning that during tensile deformation these defects are freer to move and annihilate. Another explanation remits to the models relating $\mathrm{W}-\mathrm{H}$ to precipitate size, which point out that shearable particles are less adequate in sustaining a high $\mathrm{W}-\mathrm{H}$ rate as their efficiency for dislocation pinning and/or Orowan-loop generation are low [28, 30, 32]. Assuming that shearable precipitates are small, the present results seem to point to the right direction with the exception of sample 1XS170, see Table 2. Finally, the effect of SPD on the extent of hardening by $\mathrm{Al}_{2} \mathrm{Cu}$ is clearly seen in Table 3 which shows how precipitation kinetics is remarkably accelerated by ECAP.

Table 3. Brinnel hardness of undeformed and deformed plus aged Al-4\%Cu samples

\begin{tabular}{lccc}
\hline \multicolumn{1}{c}{ Sample } & Aging $\left({ }^{\circ} \mathrm{C}\right)$ & Peak hardness $(\mathrm{HB})$ & Time for $\mathrm{HB}_{\max }(\mathrm{h})$ \\
\hline $0 \mathrm{X}$ & 170 & 99 & 20 \\
& 100 & 95 & 200 \\
1XS & 170 & 113 & 1 \\
& 100 & 122 & $>13$ \\
4XS & 170 & 120 & 2 \\
& 100 & 135 & $>50$ \\
\hline
\end{tabular}

For the alloy AA3004, the interpretation of W-H and ductility behaviour seems to be more straightforward: there is no precipitation and regardless of the intensity of deformation, the annealing heat treatments lead to a continuous decrease in the dynamic recovery rate, see Figure 9-b. Ultimate strength is maintained and ductility increases, as should be expected from a material with improved $\mathrm{W}-\mathrm{H}$ capacity. There is no possibility that the intermetallics have any role in this mechanism as they are too large and far apart. Although after deformation they are fractured by shearing, debris are still largely spaced. However, it was shown that alloy AA3004 undergoes precipitation of $\mathrm{Al}_{12}(\mathrm{Fe}, \mathrm{Mn})_{3} \mathrm{Si}$ needles [62], whose small dimension suggest them to be shearable. Therefore, further studies will be needed to assess their role on the $\mathrm{W}-\mathrm{H}$ behaviour.

Finally, it must be stressed that although uniform elongation is not a direct measure of ductility is related to it. Furthermore, it is a crucial property for deep forming processes such as hydroforming, for instance, since it indicates the deformation limits before the onset of internal damage. The present work is more concerned with the effects of precipitation on $\mathrm{W}-\mathrm{H}$, thus on $\varepsilon_{\text {unif, }}$ but graphs of $\mathrm{d} \theta / \mathrm{d} \sigma$ against total elongation are similar to those depicted in Figure 9, at least for the $\mathrm{Al}-4 \% \mathrm{Cu}$ alloy. Indeed, for group $\mathrm{S}$ of the same alloy the ratio $\varepsilon_{\text {unif }} / \varepsilon_{\text {total }}$ is in the range $0.45-0.58$, therefore is almost constant. 


\section{Concluding Remarks}

Ductility is one of the most important properties of metallic materials and the study of the phenomenon of W-H is basic - although not sufficient - to its understanding and control. For normal grain sizes, the classic models of Kocks, Estrin and Nes suitably describe how the W-H rate results from a balance between dislocation accumulation and annihilation. Furthermore, these same models explain how dislocations interact with grain boundaries, precipitates and solute atoms. Concerning nano-structured metals, it was recognized early on that high strength is concurrent with low ductility, and this behaviour has been attributed to factors such as decreased intragranular-mediated plasticity, residual stresses and dislocation locking. However, some instances of moderate ductility were observed and this led to the identification of ductility-enhancing mechanisms whose relative importance is still under study. Among these mechanisms, the interaction of dislocations with second phase precipitates seems to increase the $\mathrm{W}-\mathrm{H}$ rate by either intensifying dislocation accumulation or retarding the dynamic recovery rate, or both. In the present paper, the effects of $\mathrm{Al}_{2} \mathrm{Cu}$ precipitates on the tensile properties of an $\mathrm{Al}-\% \mathrm{Cu}$ alloy were tested with positive results in the sense that post-ECAP deformation heat treatments resulted in a good combination of strength and uniform elongation. Analysis of the flow behaviour together with microstructural observations seems to attribute the enhanced $\mathrm{W}-\mathrm{H}$ rate to a decrease in the dynamic recovery rate, in its turn due to dislocation pinning by the $\mathrm{Al}_{2} \mathrm{Cu}$ particles. As for the annealed $\mathrm{AA} 3004$ alloy, although the W-H rate was relatively low, ductility and strength were much higher than for the cold rolled (H38) alloy.

\section{References}

[1] J. Zrnik, S.V. Dobatkin and I. Mamuzic: Metabk. Vol. 47 (2008), p. 211

[2] C.Xu, Z. Horita and T.G. Langdon: Acta Mater. Vol. 55 (2007), p. 203

[3] R. Srinivasan, B. Cherukuri and P.K. Chaudhury: Mat. Sci. Forum. Vols. 503 - 504 (2006), p. 371

[4] A.A. de A. Mendes Filho, V.L. Sordi, J.B. Rubert and M. Ferrante: Mat. Sci. Forum. Vols. 584 586 (2008), p. 145

[5] R.Z. Valiev and T.G. Langdon: Progress in Mat. Sci. Vol. 51 (2006), p. 881

[6] M.A. Meyers, A. Mishra and D.J. Benson: Progress in Mat. Sci. Vol. 51 (2006), p. 427

[7] Y.T. Zhu and T.G. Langdon: JOM. Vol. 56 (2004), p. 58

[8] E.P. Prados, V.L. Sordi and M. Ferrante: Mat. Research, Vol. 11 (2008), p. 199

[9] X. Zhao, W. Fu, X. Yang and T. G. Langdon: Scripta Mater. Vol. 59 (2008), p. 542

[10] R.Z. Valiev, I.V. Alexandrov, Y.T. Zhu and T.C. Lowe: J. Mat. Res. Vol. 17 (2002), p. 5

[11] I.J. Beyerlein and L.S. Tóth: Progress in Mat. Sci. (2009), in press

[12] C. Pithan, T. Hashimoto, M. Kawazoe, J. Nagahora and K. Higashi: Mat. Sci. Eng. A Vol. 280 (2000), p. 62

[13] S. Li: Scripta Mat. Vol. 60 (2009), p. 356

[14] C.J. L. Pérez, C. Berlanga and J.Perez-Ilzarbe: Mat. Proc. Techn. Vols.143-144 (2003), p. 105

[15] A. Gholinia, P.B. Prangnell and M.V. Markushev: Acta Mater. Vol. 48 (2000), p. 1115

[16] M.V. Markushev and M. Yu Murashkin: Mat. Sci. Eng. A Vol. 367 (2004), p. 234

[17] P. Szczygiel, H.T. Roven and O. Reiso: Mat. Sci. Eng. A Vol. 493 (2008), p. 202

[18] C. Xu, M. Furukawa, Z. Horita and T.G. Langdon: Acta Mater. Vol. 53 (2005), p. 749

[19] E.F. Prados, V.L. Sordi and M. Ferrante: Mat. Sci. Forum Vols. 584-586 (2008), p. 708 
[20] M. Cai, D.P. Field and G.W. Lorimer: Mat. Sci. Eng. A Vol. 373 (2004), p. 65

[21] J. Chen, L. Lu and K. Lu: Scripta Mater. Vol. 54 (2006), p. 1913

[22] J.A. Knapp and D.M. Follstaedt: J. Mater. Res. Vol. 19 (2004), p. 218

[23] G.I. Taylor: Proc. Roy. Soc. Vol. A145 (1934), p. 362

[24] U.F. Kocks: J. Eng. Mater. Technol. (ASME-H), Vol. 98 (1976), p. 76

[25] Y. Estrin, L. S. Tóth, A. Molinari and Y. Bréchet: Acta Mat. Vol. 46 (1998), p. 5509

[26] E. Nes and K. Marthinsen: Mater. Sci. Eng. A Vol. 322 (2002), p.176

[27] M.F. Ashby, in: Strengthening Methods in Crystals, edited by A. Kelly and R.B. Nicholson, John Wiley, New York (1971), p. 137

[28] Y. Estrin, in: Unified Constitutive Laws of Plastic Deformation, edited by A.S. Krausz and K. Krausz, Academic Press, Orlando, FL (1996), p. 69

[29] F. Fazeli, W.J. Poole and C.W. Sinclair: Acta Mater. Vol. 56 (2008), p. 1909

[30] S. Esmaeili, L.M. Cheng, A. Deschamps, D.J. Lloyd and W.J. Poole: Mat. Sci. Eng. A Vols. 319-321 (2001), p. 461

[31] S. Cheng, Y.H. Zhao, Y.T. Zhu and E. Ma: Acta Mater. Vol. 55 (2007), p. 5822

[32] Deschamps, S. Esmaeili, W.J. Poole and M. Militzer: J. Physique IV France, Vol.10 (2000), p. 151

[33] A.D. Rollet, U.F. Kocks and R.D. Doherty, in: Formability and Metallurgical Structure, Edited by A.K. Sachdev and J.D.Embury, TMS, Warrendale, PA (1986), p. 211.

[34] H. Van Swygenhoven, D. Farkas and A. Caro: Phys. Rev. B Vol. 62 (2001), p. 831

[35] H. Van Swygenhoven: Mat. Sci. Forum Vols. 503-504 (2006), p. 193

[36] A. Ma, K. Suzuki, Y. Nishida, N. Saito, I. Shigematsu, M. Takagi, H. Iwata, A. Watazu and T. Imura: Acta Mater. Vol. 53 (2005), p. 211

[37] A. Ma, Y. Nishida, J. Jing-hua, N. Saito, I. Shigematsu and A. Watazu: Trans. Nonferrous Met. Soc. China, Vol. 17 (2007), p. 104

[38] N. Q. Chinh, P. Szommer, T. Csanádi and T.G. Langdon: Mat. Sci. Eng. A Vol. 434 (2006), p. 326

[39] I. Sabirov, Y. Estrin, M.R. Barnett, I. Timokhina and P.D. Hodgson: Acta Mater. 56 (2008), p. 2223

[40] D. Wolf, V. Yamakov, S.R. Phillpot, A. Mukherjee and H. Gleiter: Acta Mater. Vol. 53 (2005), p. 1

[41] E.F. Dudarev, G.P. Pochivalova, Yu. R. Kolobov, E.V. Naydenkin and O.A. Kashin: Mat. Sci. Eng. A Vol. 503 (2009), p. 58

[42] M. Meyers and E. Ashworth: Philos. Mag. A Vol. 46 (1982), p. 737

[43] R.Z. Valiev, V.Yu. Gertsman and O.A. Kaibyshev: Phys. Stat. Sol. (a) Vol. 97 (1986), p. 11

[44] J. Y. Huang, Y. T. Zhu, H. Jiang and T. C. Lowe: Acta Mater. Vol. 49 (2001), p. 1497

[45] E. Ma: Scripta Mater. Vol. 49 (2003), p. 663

[46] R.K. Islamgaliev and R.Z. Valiev: Phys. Met. Metall. Vol. 87 (1999), p. 215

[47] T. Fujita, Z. Horita and T.G. Langdon: Mat. Sci. Eng. Vol. 371 (2004), p. 241 
[48] J. Ribbe, G. Schmitz, Y. Amouyal, Y. Estrin and S.V. Divinski: Mat. Sci. Forum, Vols. 584586 (2008), p. 380

[49] X. Wu, W. Xu and K. Xia: Mat. Sci. Eng. A Vol. 493 (2008), p. 241

[50] V.L. Tellkamp, A. Melmed and E.J. Lavernia: Metall. Mat. Trans. Vol. 32A (2001), p. 2335

[51] B.Q. Han, Z. Lee, D. Witkin, S. Nutt and E.J. Lavernia: Metall. Mat. Trans. Vol. 36A (2005), p. 957

[52] Y. Wang, M. Chen, F. Zhou and E. Ma: Nature 419 (2002) 912

[53] S.H. Xia, L.V. Vychigzhanina, J.T. Wang and I.V. Alexandrov: Mat. Sci. Forum, Vols. 584586 (2008), p. 315

[54] G.V. Nurislamova, R.K. Islamgaliev and R. Valiev: Mat. Sci. Forum Vols. 503-504 (2006), p. 579

[55] M. Murayama, Z. Horita and K. Hono: Acta Mater. Vol. 49 (2001), p. 21

[56] N.Q. Chinh, J. Gubicza, T. Czeppe, J. Lendvai, Z. Hegedüs, C. Xu and T.G. Langdon: Mat. Sci. Forum, Vols. 584-586 (2008), p. 501

[57] R./B. Nicholson, in: Phase Transformations, edited by A.I. Aaronson, American Society for Metals, Metals Park, Ohio (1970).

[58] S. Esmaeili, D.J. Lloyd, and W.J. Poole: Acta Mater. Vol. 51 (2003), p. 2243

[59] L.M. Cheng, W.J. Poole, J.D. Embury, and D.J. Lloyd: Metall. Mat. Trans. Vol. 34A (2003), p. 2473

[60] W.J. Kim, C.S. Chung, D.S. Ma, S.I. Hong and H.K. Kim: Scripta Mat. Vol. 49 (2003), p. 333

[61] K.Ohashi, T.Fujita, K. Kaneko, Z. Horita and T.G. Langdon: Mat. Sci. Eng. A Vol. 437 (2006), p. 240

[62] L. Chen and J.G. Morris: Scripta Metall. Vol. 18 (1984), p. 1365 